\title{
Laser powder bed fusion additive manufacturing of copper wicking structures: fabrication and capillary characterization
}

\author{
Adnen Mezghani, Abdalla R. Nassar and Corey F. Dickman \\ Applied Research Laboratory, The Pennsylvania State University, University Park, Pennsylvania, USA, and \\ Eduardo Valdes and Raul Alvarado \\ SET Group LLC, Conshohocken, Pennsylvania, USA
}

\begin{abstract}
Purpose - An integral component in heat pipes (HPs) and vapor chambers (VCs) is a porous wicking structure. Traditional methods for manufacturing wicking structures within HPs and VCs involve secondary manufacturing processes and are generally limited to simple geometries. This work aims to leverage the unprecedented level of design freedom of laser powder bed fusion (LPBF) additive manufacturing (AM) to produce integrated wicking structures for HPs and VCs.

Design/methodology/approach - Copper wicking structures are fabricated through LPBF via partial sintering and via the formation of square, hexagonal and rectangular arrangements of micro-pins and micro-grooves, produced in multiple build directions. Wicks are characterized by conducting capillary performance analysis through the measurement of porosity, permeability and capillary rate-of-rise.

Findings - Copper wicking structures were successfully fabricated with capillary performance, K/reff, ranging from $0.186-1.74 \mu \mathrm{m}$. The rectangular-arrangement micro-pin wick presented the highest performance.

Originality/value - This work represents the first published report on LPBF AM of copper wicking structures for HPs/VCs applications and represents foundational knowledge for fabricating complete assemblies of copper VCs and HPs through LPBF AM.
\end{abstract}

Keywords Additive manufacturing, Copper, Vapor chamber, Porous materials, Thermal management, Wick

Paper type Research paper

\section{Introduction}

Thermal management of high heat-flux electronic devices poses a significant engineering challenge. As an alternative to conventional heat exchangers, heat pipes (HPs) and vapor chambers (VCs) have gained significant attention in the past several decades, given their very high thermal conductance and passive cooling capability (Elnaggar and Edwan, 2016; Lips et al., 2016; Reay et al., 2014). Integral to the operation of these two-phase thermal management systems is a conformal, porous wick, which transports liquid from the heat sink to the heat source via capillary pressure. Once evaporated, the vapor rapidly travels toward the heat sink. Heat transfer is, thus, achieved through cyclic evaporation and condensation.

Conventional HPs and VCs are limited in geometry and complexity to pipe- or plate-like geometries and involve secondary manufacturing processes for porous wick production and assembly (e.g. sintering, welding, electroplating and vapor or chemical deposition). Laser powder bed fusion (LPBF) additive manufacturing (AM) offers the potential for

The current issue and full text archive of this journal is available on Emerald Insight at: https://www.emerald.com/insight/1355-2546.htm

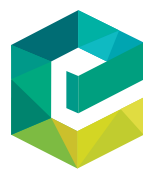

Rapid Prototyping Journal

27/6 (2021) 1181-1188

(C) Emerald Publishing Limited [ISSN 1355-2546]

[DOI 10.1108/RPJ-01-2021-0016] complexity and customization in HP and VC geometries and function, and eliminating secondary wick manufacturing steps.

Here, we demonstrate, for the first time, LPBF of sintered copper wicks. Moreover, the fabrication of micro-pin and grooved copper wicking structures via LPBF for capillary wicking applications is reported. This work, thus, demonstrates the feasibility of producing pure copper wicking structures via $\mathrm{LPBF}$, provides reproducible processing parameters and recommends build-up geometries for production.

\subsection{Quantifying capillary performance of wicking structures}

Within a wick, liquid transport is driven by a pressure gradient in the direction of lower liquid saturation. At the liquid front illustrated in Figure 1, three pressure gradients are in equilibrium:

$$
P_{c}=P_{h}+P_{f}
$$

Funding: This work was supported by SET Group, LLC though prime contract number $80 \mathrm{NSSC} 18 \mathrm{C} 0125$ from the National Aeronautics and Space Administration under FY 2017 SBIR topic S3.03. The views and conclusions contained in this document are those of the authors and should not be interpreted as necessarily representing the official policies, either expressed or implied, of the government.

Received 18 January 2021

Revised 21 April 2021

Accepted 26 April 2021 
Figure 1 Capillary flow of water (blue) in a homogeneous sintered wick and a micro-structured wick

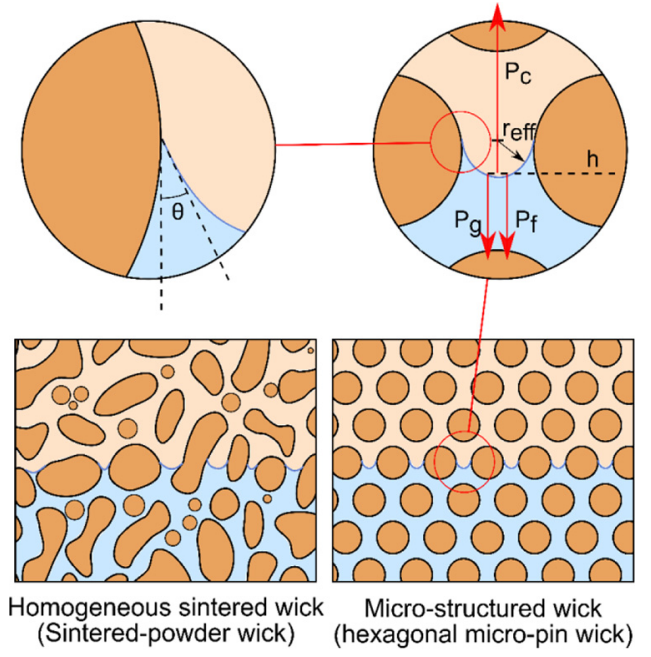

Notes: $\mathrm{P}_{c}$ is capillary pressure, $\mathrm{P}_{\mathrm{g}}$ is hydrostatic pressure, $\mathrm{P}_{\mathrm{f}}$ is the pressure generated from viscous friction, $\mathrm{h}$ is liquid meniscus height, reff is the liquid meniscus radius of curvature and $\theta$ is the contact angle

The capillary pressure $\left(P_{c}\right)$, which drives the liquid transport, is counteracted by hydrostatic pressure $\left(P_{h}\right)$ and pressure generated from viscous friction $\left(P_{f}\right)$. An ideal wick exhibits a balance of high capillary pressure as well as high permeability. Capillary pressure increases as the size of pores within the wick decreases. However, decreasing pore size generally decreases permeability and thus increases viscous friction. To capture the effects of these two opposing parameters, capillary performance parameters are generally used; these include the ratio of permeability to effective pore radius $\left(K / r_{\text {eff }}\right)$ and the product of capillary pressure and permeability $\left(P_{c} \cdot K\right)$ - see Jafari et al. (Jafari et al., 2018) for derivations of these parameters. Here, we aim to demonstrate AM copper wicks with a capillary performance $\left(K / r_{\text {eff }}\right)$ on par with reported literature (Ameli et al., 2013; Esarte et al., 2017; Jafari et al., 2018; Richard et al., 2017).

\subsection{Manufacturing process of porous wicks via laser powder bed fusion}

Recently, AM of wicks has received significant attention (Ameli et al., 2013; Esarte et al., 2017; Jafari et al., 2018; Jafari and Wits, 2018; Richard et al., 2017). Most studies have investigated easy-to-print AM alloys, including $316 \mathrm{~L}$ stainless steel (Esarte et al., 2017; Jafari et al., 2018; Richard et al., 2017) and the AlSil0Mg aluminum alloy (Ameli et al., 2013). Ameli et al. (2013) demonstrated one-step fabrication, via LPBF, of a complete assembly of an aluminum HP. Jafari et al. (2018) successfully fabricated, via LPBF, and characterized octahedral lattice-structure wicks from $316 \mathrm{~L}$ stainless steel of unit length of $0.5 \mathrm{~mm}$, creating periodic and ordered pores of approximately $0.23 \mathrm{~mm}$ in diameter. However, the printability of wicking structures from pure copper via LPBF has not been reported, possibly because AM of pure copper is considered more difficult than other material systems (e.g. stainless steel, titanium and Inconel), due to the significantly higher reflectivity of the laser and thermal conductivity of pure copper. High reflectivity and thermal conductivity can lead to instability in the melt pool during processing, which leads to more defects. Despite the increased difficulty, AM of pure copper has great potential for next-generation thermal management devices due to copper's superior thermal conductivity (Jafari and Wits, 2018).

Somewhat analogous to traditional sintered wick fabrication, AM of partially melted wicks via adjustment of laser power and translation speed has been demonstrated in $316 \mathrm{~L}$ steel by Richard et al. (2017). A similar approach has been used for loop HP wick production by Esarte et al. (2017). AM of single-layer partially melted wicks has been demonstrated by Jafari et al. (2020) by using pulse wave emission.

Non-AM wick fabrication processes for periodic microstructures, such as electroplating of square, hexagonal and rectangular pin arrangements (Cho et al., 2018), as well as micro machining of v-grooves, Zeng et al. (2017) have been demonstrated. Cho et al. (2018) found that, among silica-plated copper micro-pin structures with $45-80 \%$ porosity, rectangular arrangement provided the highest permeability, capillary performance and directionality in fluid flow (highest permeability along widest tracks). Other works have confirmed these findings (Hale et al., 2014a; Hale et al., 2014b), showing that rectangular arrangement provide higher capillary performance than the square arrangement due to a higher permeability with similar capillary pressure. However, rectangular pins show significant anisotropy in fluid flow; in comparison, hexagonal arrangement performed most similarly to sintered wicks in isotropy of capillary flow. AM of AlSi10Mg pillar-like micrometer/millimeter size structures via $\mathrm{LPBF}$ has been investigated for applications in high-temperature surface cooling (Wang et al., 2018). Thus far, the capillary performance of AM pillar-like microstructures has not been investigated.

In applications where directional flow is more suited (e.g. HPs) and gravity forces are low (i.e. space applications) (Reay et al., 2014), micro grooves are an easy-to-fabricate alternative to pin arrangements. Groove cross-section and composition can be used to improve capillary performance, with triangular (Zeng et al., 2017) and composite (Deng et al., 2013; Tang et al., 2010) micro v-grooves, the latter containing a sintered powder layer that provides higher capillary pressures than square grooves. The addition of reentrant structures on the vgroove channels, which increased the achieved capillary pressure of the groove surface, further improves performance (Zeng et al., 2017).

Here, methods for fabricating partially sintered and micro-pin arrangements via LPBF are presented (Section 2.1). Wick porosity, permeability and capillary performance are quantified (Section 3). Lastly, generalizable strategies for production of copper wicking structures for VC and HP applications are discussed (Section 4), providing a pathway for future development.

\section{Material and methods}

\subsection{Sample design and fabrication}

To represent a cross-section of a VC, 1-mm-thick wicks were printed atop 1-mm-thick bases, with sides measuring 
$25.4 \times 25.4 \mathrm{~mm}$ (Figure 2(a)). Micro-pins, micro-grooves and sintering wicks were produced. Micro-pin arrangements included square, hexagonal and rectangular. Figure 3 lists and illustrates these arrangements with an intended feature diameter/ width of approximately $200 \mu \mathrm{m}$. Square-arrangement micropins were also built horizontally, vertically, inclined at $45^{\circ}$ with the pins facing upward (Figure 2(b)).

The micro-pin and micro-groove samples of this study were processed with a laser power of $360 \mathrm{~W} \pm 5 \%$, a laser scan speed of $590 \mathrm{~mm} / \mathrm{s} \pm 5 \%$ and a single-hatch strategy (i.e. a single laser pass). Studies with great insight on laser processing parameters

Figure 2 Illustration of (a) sample geometry, and (b) build orientations: horizontal (left), vertical (middle), and inclined at $45^{\circ}$ (right)

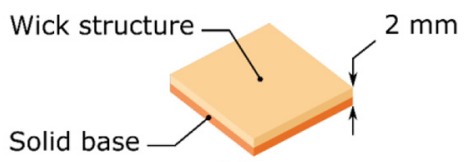

(a)

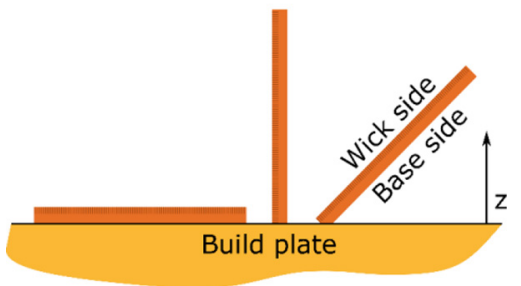

(b) for AM of pure copper and copper alloys, which provide minimum energy density requirements and typical nominal parameters, can be found in several studies (Colopi et al., 2019; El-Wardany et al., 2018; Pogson et al., 2003; Popovich et al., 2016; Robinson et al., 2021; Zhang et al., 2020). However, it is important to be aware of the differences in setup (e.g. laser beam diameter, layer height, build plate material), the presence of alloying elements and limitations of the system (e.g. maximum laser power output).

Sintered powder wicks were produced by lowering laser energy density (LED = power/speed) to sinter, rather than melt the copper powder. A laser power of $100 \mathrm{~W}$ was selected, and laser scan speeds were increased to 1.6 and 2.1 times the nominal value, achieving LED reductions of six and eight times the nominal value. Hatching was conducted with a hatch spacing of $0.13 \mathrm{~mm}$ and a $90^{\circ}$ rotation between layers. Processing parameters are provided in Table 1 along with build orientations: horizontal, vertical and inclined at $45^{\circ}$.

Samples were fabricated on an EOS M280 LPBF system, equipped with a $400 \mathrm{~W}$ maximum power ytterbium-doped fiber laser focused to an ISO 11146-1 measured second moment diameter of $70 \mu \mathrm{m}$. Feedstock copper powder $(99.6 \%$ $\mathrm{Cu}$ ) was procured from Elementum $3 \mathrm{D}$ with particle size distribution (PSD) presented in Figure 4. The D10, D50, D90, from the PSD analysis are 13.5, 30.5 and $56.1 \mu \mathrm{m}$, respectively. All processing occurred in an argon environment with a maximum oxygen concentration less than $1,000 \mathrm{ppm}$. A constant layer thickness of $40 \mu \mathrm{m}$ was used together with a flexible silicon recoater blade.

After fabrication, samples were brushed to remove powder and stress relieved at $650^{\circ} \mathrm{C}$ for $2 \mathrm{~h}$, then furnace cooled under

Figure 3 Implemented micro-structure arrangements strategies. Intended build geometries are illustrated in the last column, where pin/groove diameter/width is set to be approximately $200 \mu \mathrm{m}$

\begin{tabular}{|c|c|c|c|c|}
\hline Sample & $\begin{array}{l}\text { Micro-structure } \\
\text { arrangement }\end{array}$ & unit size $(\mu \mathrm{m})$ & Build orientation & $\begin{array}{l}\text { Illustration showing pin or groove } \\
\text { arrangement }\end{array}$ \\
\hline P-S-400-H & \multirow{3}{*}{ Square (S) } & $I=400$ & Horizontal & \\
\hline P-S-400-V & & $\mathrm{I}=400$ & Vertical (V) & \\
\hline P-S-400-IU & & $\mathrm{I}=400$ & $\begin{array}{l}\text { Inclined } 45^{\circ} \text { with } \\
\text { pins up (IU) }\end{array}$ & \\
\hline P-H-350-H & Hexagonal (H) & $I=350$ & Horizontal & \\
\hline P-R-450-600-H & & $I=450 ; S=600$ & Horizontal & \\
\hline P-R-450-800-H & & $\mathrm{I}=450 ; \mathrm{S}=800$ & Horizontal & \\
\hline G-600-H & & $I=600$ & Horizontal & \\
\hline G-800-H & & $I=800$ & Horizontal & \\
\hline
\end{tabular}


Table 1 Processing parameters used to fabricate the sintered-powder wick samples

\begin{tabular}{lcccccc}
\hline \multirow{2}{*}{ Sample ID } & Power (W) & Scanning speed (mm/s) & Hatch spacing (mm) & Build orientation & LED (J/mm) & LED reduction multiplier \\
\hline S-100-504-I & 100 & 504 & 0.16 & Inclined 45 & 0.198 & 6 \\
S-100-672-H & 100 & 672 & 0.16 & Horizontal & 0.149 & 8 \\
S-100-672-V & 100 & 672 & 0.16 & Vertical & 0.149 & 8 \\
S-100-672-I & 100 & 672 & 0.16 & Inclined 45 & 0.149 & 8 \\
\hline
\end{tabular}

Figure 4 PSD of copper powder stock

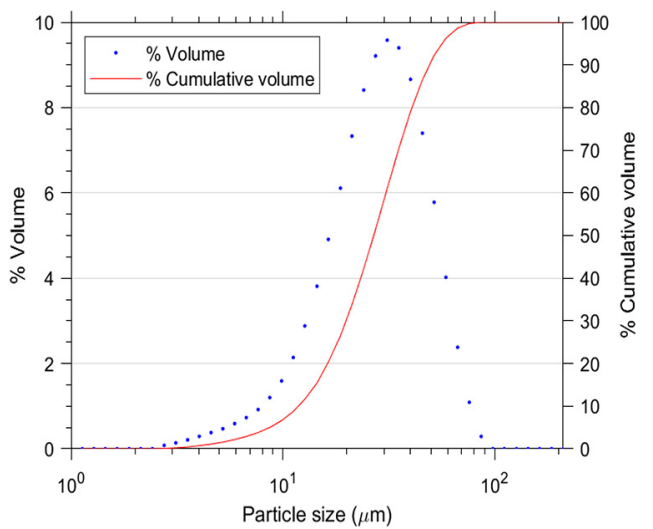

nitrogen. Finally, samples were removed from the build plate via electrical discharge machining (EDM).

Prior to testing, samples were cleaned and dried following (Reay et al., 2014; Singh et al., 2009; Tang et al., 2017) with minor adjustments, as follows. Samples were submerged in $2 \mathrm{M}$ hydrochloric acid for $1 \mathrm{~min}$, then rinsed with deionized water to remove carbon and oxides residue. To remove remaining oils, contaminants or loose powder, samples were agitated in an ultrasonic acetone bath for $15 \mathrm{~min}$, then rinsed in an ultrasonic DI water bath for $10 \mathrm{~min}$. Finally, samples were dried in a furnace at $150^{\circ} \mathrm{C}$ for $30 \mathrm{~min}$, followed by air cooling for $5 \mathrm{~min}$. The samples were subsequently tested for rate-of-rise, porosity and permeability, respectively.

\subsection{Characterization and data analysis}

\subsubsection{Porosity measurement}

Porosity was measured using the density method: comparing the theoretical density of copper to the apparent density of the wick:

$$
\varepsilon_{a}=1-\frac{m_{w}}{V_{w} \rho_{s}}
$$

where $\varepsilon_{a}, m_{w}, V_{w}$ and $\rho_{s}$ are the wick's apparent porosity, mass, external volume and the density of copper, respectively. Porosity measurements from the density method were juxtaposed with true porosity $\left(\varepsilon_{t}\right)$, measured using the Archimedes method, in which the wick is saturated with a wetting liquid through:

$$
\varepsilon_{t}=\frac{1}{1+\frac{m_{w} \rho_{l}}{m_{l} \rho_{s}}}
$$

where $m_{l}$ and $\rho_{l}$ are the mass and density of the infiltrating liquid, respectively. The Archimedes method only measures porosity interconnected to the surface, while the density method includes interconnected as well as trapped porosity in the wick. By comparing the porosity measurements of these two methods, the percent amount of trapped porosity in a wick can be calculated through $\% \varepsilon_{\text {trapped }}=\left(\varepsilon_{a}-\varepsilon_{t}\right) \times 100 \%$.

\subsubsection{Permeability measurement}

Permeability was measured using a form of Darcy's law (i.e. forced-flow method) describing the pressure drop for steadystate laminar fluid flow through porous media (Reay et al., 2014) through:

$$
\Delta P=\frac{\mu l \dot{m}}{\rho K A}
$$

where $\mu$ is the viscosity, $\rho$ is the density of the flowing liquid, $K$ is the permeability, $l$ is the length of the wick along the fluid flow, $A$ is the cross-sectional area of the wick perpendicular to fluid flow and $m$ is the fluid mass flow rate. Though forced-flow methods are common (Ameli et al., 2013; Choi et al., 2013; Deng et al., 2013; Esarte et al., 2017; Espinosa et al., 2012; Jafari et al., 2018; Semenic et al., 2008; Singh et al., 2009), we note that high fluid flow velocities lead to failure of Darcy's law and result in unreliable permeability measurements. In this work, we ensured flow velocity was below the transition velocities found in similar studies $(0.07-0.1 \mathrm{~m} / \mathrm{s}$ ) (Boomsma and Poulikakos, 2002; Jafari et al., 2018). Samples were placed in a flow housing, schematically shown in Figure 5. Thin rubber strips were placed around the sample to ensure a watertight fit and eliminate any flow bypassing the sample. Before pressure and flow rate measurements, samples were flushed with water for 5 min to eject air bubbles. A scale was also used to validate the measured flow rate.

\subsubsection{Capillary rate-of-rise test}

An infrared (IR) camera was used to visualize the rising DI water meniscus and measure the liquid rate of rise $\left(\frac{d h}{d t}\right)$, as illustrated in Figure 6, following Tang et al. (2010). To reduce evaporation from the reservoir and wick, tests were conducted within an enclosure with a relative humidity of $70-95 \%$.

Capillary performance $\left(K / r_{e f f}\right)$ was derived using rate-of-rise, wetting liquid properties and wick porosity as follows. The rate of rise expression being:

$$
\frac{d h}{d t}=\frac{2 \sigma}{\mu \varepsilon_{t}} \frac{K}{r_{e f f}} \frac{1}{h}-\frac{\rho g K}{\mu \varepsilon_{t}}
$$


where $\sigma$ is surface tension of the liquid, $g$ is the gravitational acceleration and $h, \frac{d h}{d t}, \mu, \rho, \varepsilon_{t}, K$ are defined previously. Substituting $\frac{d h}{d t}$ with $y$ and $\frac{1}{h}$ with $x$, equation (5) becomes a linear equation as:

$$
y=\frac{2 \sigma}{\mu \varepsilon_{t}} \frac{K}{r_{e f f}} x-\frac{\rho g K}{\mu \varepsilon_{t}}
$$

having a slope of $\left(\frac{2 \sigma}{\mu \varepsilon_{t}} \frac{K}{r_{e f f}}\right)$ that contains the capillary performance parameter $\left(\frac{K}{r_{\text {eff }}}\right)$ and known liquid and wick properties $\left(\frac{2 \sigma}{\mu \varepsilon_{t}}\right)$. An explicit solution to equation (5) is found by fitting height vs time data to a natural log curve of the form:

$$
h=a \ln (t)+b
$$

From which, the inverse height $(x=1 / h)$ and rate of rise $(y=d h / d t)$ are calculated for the initial capillary rise duration. Finally, the slope of a linear fit to equation (6) is determined and the capillary performance $\left(\frac{K}{r_{e f f}}\right)$ is calculated.

\section{Results}

Several types of copper wicking structures were successfully additively manufactured and characterized. Figure 7 presents top-view optical images of fabricated (a,c,d) micro-pin, (b) micro-groove and (e) sintered wicks. Vertical and inclined wicks were also successfully fabricated (Figure 7(f)).

The capillary rate-of-rise was determined from IR video, exemplified in Figure 8, and fitted to a natural log curve with a coefficient of determination, i.e. goodness-of-fit, $\left(R^{2}\right)$ of 0.98-0.99. The micro-structured wick samples of this study exhibited capillary performance $\mathrm{K} / \mathrm{r}_{\text {eff }}$, ranging from 0.530-1.744 $\mu \mathrm{m}$, comparable to other AM micro-structured

Figure 5 A schematic of the permeability test setup

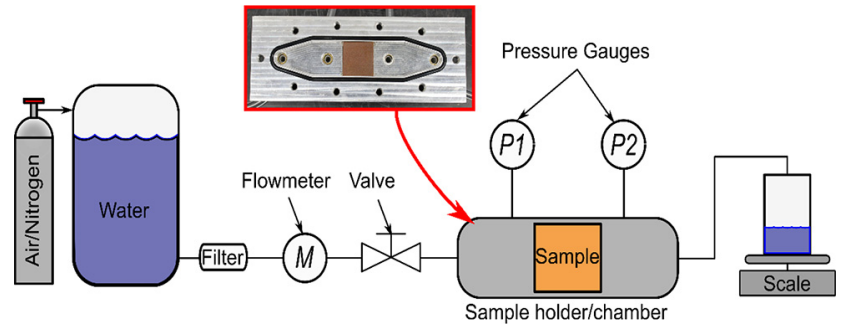

Figure 6 Capillary rate-of-rise test setup used to capture IR videos of the capillary rise of water through the wick samples

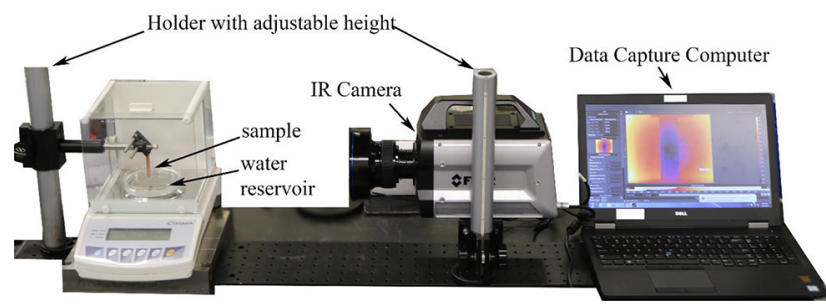

Figure 7 Optical images of some of the fabricated wick samples

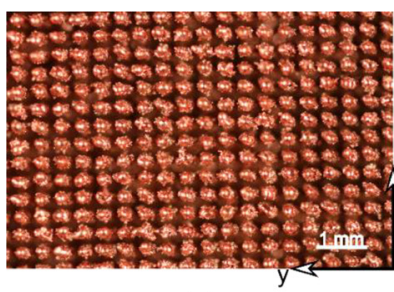

(a)

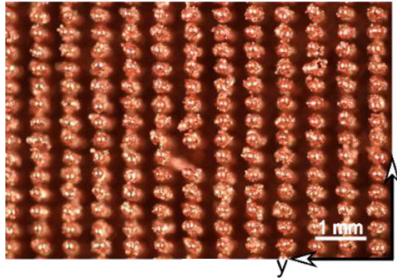

(c)

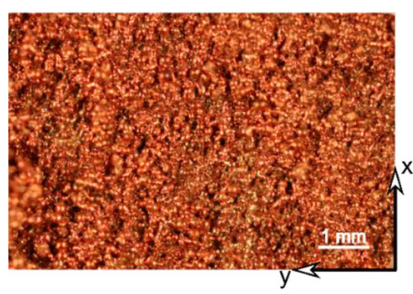

(e)

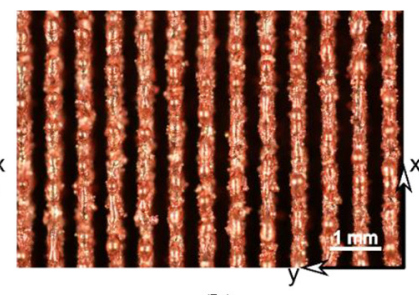

(b)

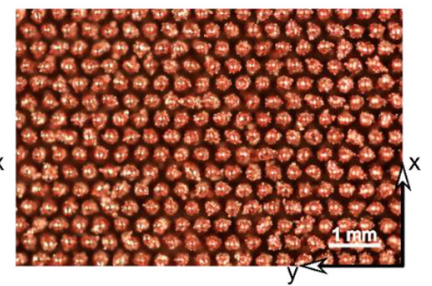

(d)

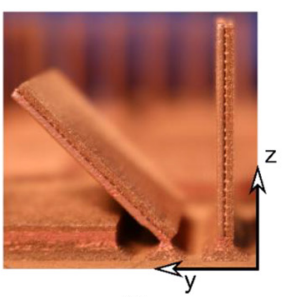

(f)
Notes: (a) Square arrangement "P-S-400-H", (b) groove "G-600H", (c) rectangular arrangement "P-R-350-600-H", (d) hexagonal arrangement "P-H-400-H", (e) sintered-powder "S-100-672-H"; (f) vertical and inclined sintered powder wicks. The $\mathrm{z}$-axis is aligned with the build direction

wicks, e.g. $\mathrm{K} / \mathrm{r}_{\text {eff }}=1.04 \mu \mathrm{m}$ (Jafari et al., 2018) and $\mathrm{K} / \mathrm{r}_{\text {eff }}=$ $2.04 \mu \mathrm{m}$ (Ameli et al., 2013).

Figure 9 presents a plot of the capillary performance $\mathrm{K} / \mathrm{r}_{\text {eff }}$ against true porosity of the fabricated samples and other AM samples. Measured permeability is presented in Figure 10.

\section{Discussion}

\subsection{Capillary performance comparison}

Micro-pin wicks with rectangular pin arrangement and 450$600 \mu \mathrm{m}$ pin spacing showed the best capillary performance and were similar to the performance of electroplated copper micropins (Cho et al., 2018). Micro-pins in a rectangular arrangement are also more permeable compared to other pin arrangements and sintered-powder wicks, shown in Figure 11. This is due to the presence of larger flow channels in a rectangular pin arrangement, which results in larger permeability to liquid flow, and with the combination of small pin-to-pin spacing, a higher overall capillary performance is achieved - this also reinforces the findings of Hale et al. (2014a) and Hale et al. (2014b).

Sintered-powder wicks exhibited $\mathrm{K} / \mathrm{r}_{\text {eff }}$, from $0.186-$ $0.247 \mu \mathrm{m}$, comparable to traditionally sintered-powder wicks, namely, $\mathrm{K} / \mathrm{r}_{\text {eff }}=0.192 \mu \mathrm{m}$ (Semenic et al., 2008), 
Adnen Mezghani et al.

Figure 8 Snapshots of the rate-of-rise IR video at different time stamps in seconds

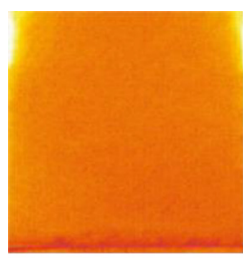

$\mathrm{t}=0.0$

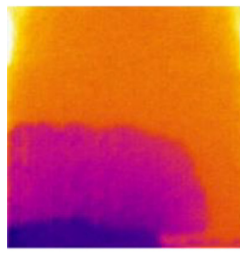

$\mathrm{t}=0.3$

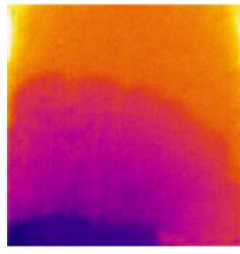

$\mathrm{t}=0.6$

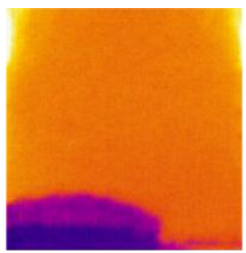

$\mathbf{t}=0.1$

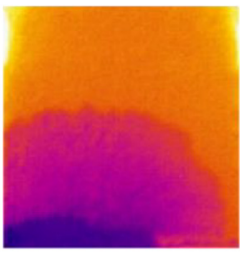

$\mathbf{t}=0.4$

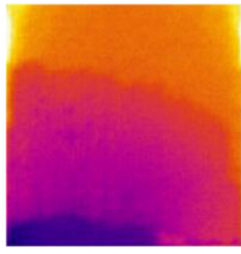

$t=0.7$

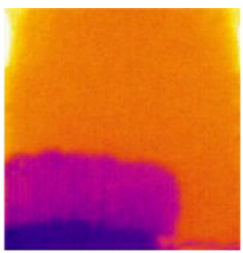

$\mathbf{t}=0.2$

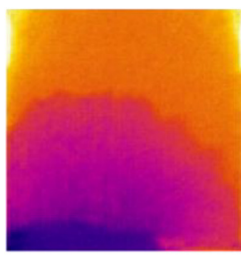

$\mathbf{t}=0.5$

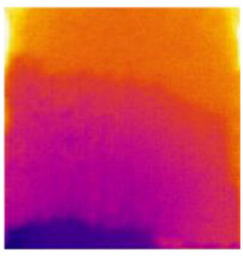

$\mathbf{t}=0.8$
Notes: Wick sample shown is P-R-450-600-H and the working fluid is deionized water

Figure 9 Capillary performance $\left(K / r_{\text {eff }}\right)$ and porosity of successfully tested samples, with comparison to other AM wicks as follows

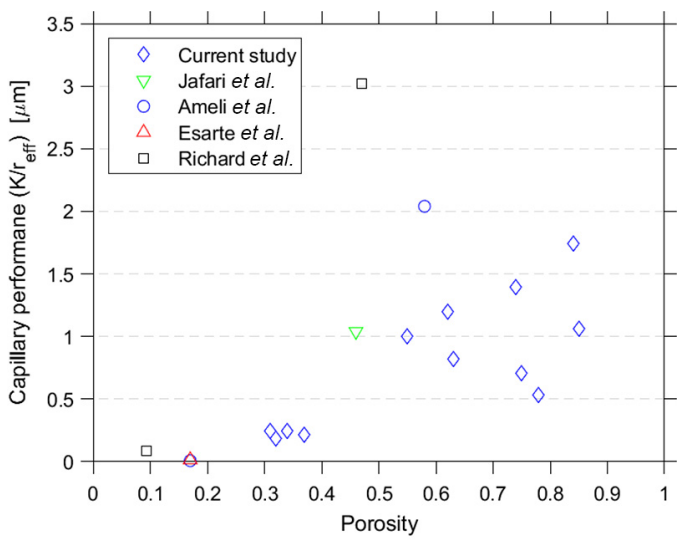

Sources: 316L stainless steel (Esarte et al., 2017; Jafari et al., 2018; Richard et al., 2017) and AlSi10Mg (Ameli et al., 2013)

$\mathrm{K} / \mathrm{r}_{\text {eff }}=0.405 \mu \mathrm{m}$ (Singh et al., 2009) and $\mathrm{K} / \mathrm{r}_{\text {eff }}=0.603 \mu \mathrm{m}$ (Deng et al., 2013). A positive correlation exists between the true porosity of sintered-powder wicks and capillary performance, shown in Figure 11. This indicates that further increasing the capillary performance is possible by increasing porosity (e.g. by further reducing LED). Because the density of the copper built with nominal LED resulted in $>99 \%$ density,
Volume $27 \cdot$ Number $6 \cdot 2021 \cdot 1181-1188$

Figure 10 Measured permeability of five wicking samples

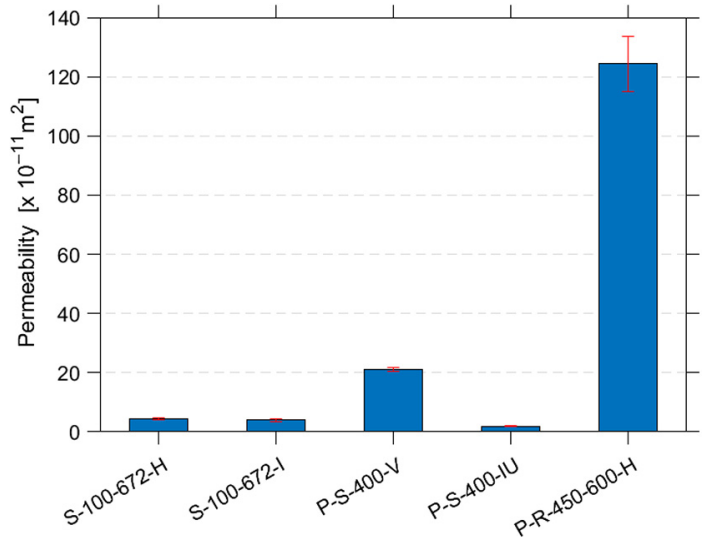

Figure 11 Plot of the capillary performance parameter $\left(K / r_{\text {eff }}\right)$ against porosity of the sintered-powder wicks in the current study and a number of non-AM sintered wicks as follows

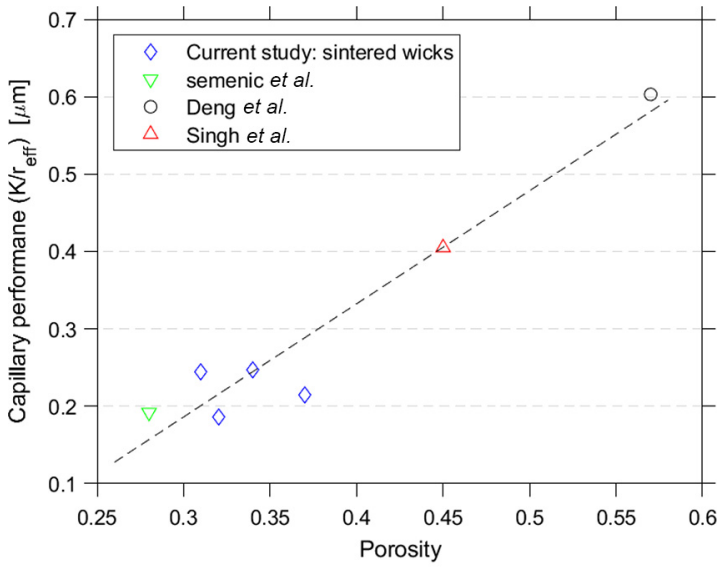

Sources: Spherical copper powder (Semenic et al., 2008; Singh et al., 2009) and irregular copper powder (Deng et al., 2013)

any inherent porosity in the $1-\mathrm{mm}$-thick solid base that is fabricated with the wicking structure is unlikely to affect wick performance.

\subsection{Interconnectedness of the porosity}

Lowering LED increased interconnectedness of the porosity in sintered-powder wicks (Figure 12(a)). Thus, low LED, is desirable and leads to higher permeability. Micro-structured samples with larger spacing also exhibited less trapped porosity compared to samples with smaller spacing between pins or grooves (Figure 12(b)). This correlation is most evident in micro-grooved wicks. We also note that irregularities in the shape and surface roughness of micro structures could cause adjacent pins/grooves to fuse and trap pores.

\subsection{The effect of sample build orientation}

For the sintered-powder wicks, the vertical and inclined samples are $9-16 \%$ less porous (in terms of true porosity, $\varepsilon_{t}$ ) 
Figure 12 Plot of percent trapped porosity against

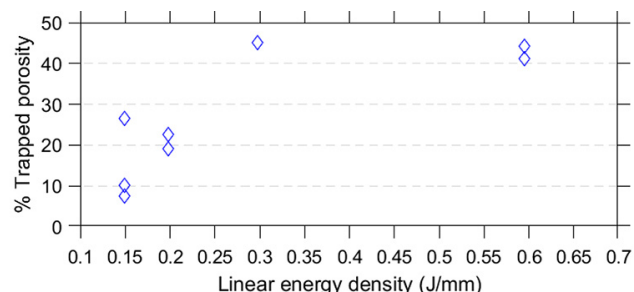

(a)

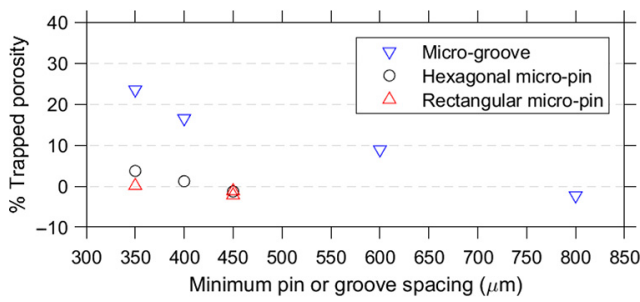

(b)

Notes: (a) linear energy density of sintered wick samples, and (b) minimum pin-to-pin or groove-to-groove spacing in the wick structure

compared to the horizontally fabricated sample. We speculate that this is due to the difference in heat dissipation. Most heat generated during fabrication is dissipated through the wick's dense base and into the build plate. Vertical and inclined samples cool slower because the cross-sectional area available for heat dissipation is significantly smaller, compared to the horizontal orientation. This phenomenon has been described by Krauss et al. (2015).

For the square-arrangement micro-pin wicks, vertically fabricated samples had more trapped porosity compared to the horizontal and inclined samples. The micro-pins in the vertically fabricated sample are essentially overhanging with an angle of $0^{\circ}$ from the horizontal plane. Lacking support, such overhanging structures can deflect (e.g. sag or curl upwards) and may fuse to adjacent pins, which can result in trapping pores (i.e. less interconnected porosity).

\subsection{Challenges in the development of laser powder bed fusion additive manufacturing of $\mathrm{Cu}$ wicks}

Production of the reported samples proved challenging due to inherent limitations of existing computer-aided design (CAD) software and AM digital workflows. CAD modeling of sinteredpowder and micro-structured wicks requires significantly different strategies. Whereas, modeling of sintered structures is possible using a single conformal body bordering a solid surface, micro-structured wicks require modeling of individual pin or groove structures. Hence, for micro-structured wicks, the number of modeled elements, and consequently the CAD file size, is significantly larger than that of the sintered-powder wick. Translation of CAD files containing thousands of cylindrical elements to the standard STL format, used by AM data preparation software, exceeds the capabilities of most commercial workstations and would not have been possible for the micro-structures presented here. Overcoming this hurdle requires the use of proprietary software tools - in this work, such tools were produced by the researchers and are beyond the scope of the current work - which, rather than create surface representations of pins and grooves, encapsulate simplified laser paths directly within slice or native build plan formats. It is recommended for future research efforts into micro-structured wicks to pursue a similar path.

It is the authors' perspective that the potential bottlenecks in the adoption and implementation of AM wicks are mostly in the digital workflow. Currently, sintered wicks are much easier to implement than micro-pin and micro-groove wicks, and hence merit further research to improve wick performance. Nonetheless, all types of wicks are additively manufacturable.

\section{Conclusions}

This work provides experimental validation of the printability of porous copper wicks in the form of sintered-powder, micro-pin and micro-groove wicking structures using LPBF AM in multiple build orientations. The achieved capillary performance, $\mathrm{K} / \mathrm{r}_{\text {eff }}$ of sintered-powder and micro-structured wicks ranged from $0.186-$ $1.744 \mu \mathrm{m}$. The micro-pin wick with rectangular pin arrangement of $450-600 \mu \mathrm{m}$ pin spacing provided the best capillary performance and permeability compared to other pin arrangements. Capillary performance for almost all microstructured samples, nonetheless, were comparable to the best performance reported in previous publications on $\mathrm{AM}$ wicks, i.e. $\mathrm{K} / \mathrm{r}_{\text {eff }}=1.04 \mu \mathrm{m}$ (Jafari et al., 2018) and $\mathrm{K} / \mathrm{r}_{\text {eff }}=2.04 \mu \mathrm{m}$ (Ameli et al., 2013). Sintered-powder and micro-pin wicks were printed vertically and inclined at $45^{\circ}$ without additional support structures, indicating the possibility of fabricating VCs/HPs assemblies in various orientations and inclination angles without requiring additional internal support structures.

The successful fabrication of these sintered-powder and microstructured wicking samples in multiple build orientation via LPBF AM indicate the feasibility of additively manufactured copper HPs and VCs with integrated wicking structures. Ongoing work seeks to further optimize processing parameters. In particular, the determination of ideal parameters and ranges, as functions of wick orientation and structure is an appropriate area of future research, as well as the investigation of other self-supporting microstructured wick designs for other build inclination angles.

\section{References}

Ameli, M., Agnew, B., Leung, P.S., Ng, B., Sutcliffe, C.J., Singh, J. and McGlen, R. (2013), "A novel method for manufacturing sintered aluminium heat pipes (SAHP)", Applied Thermal Engineering, Vol. 52 No. 2, pp. 498-504.

Boomsma, K. and Poulikakos, D. (2002), "The effects of compression and pore size variations on the liquid flow characteristics in metal foams", fournal of Fluids Engineering, Vol. 124 No. 1, p. 263.

Cho, S., Tummala, R. and Joshi, Y. (2018), "Capillary performance of micropillar arrays in different arrangements", Nanoscale and Microscale Thermophysical Engineering, Vol. 22 No. 2, pp. 97-113.

Choi, J., Sano, W., Zhang, W., Yuan, Y., Lee, Y. and Borca-Tasciuc, D.-A. (2013), "Experimental investigation on sintered porous wicks for miniature loop heat pipe 
applications", Experimental Thermal and Fluid Science, Vol. 51, pp. 271-278.

Colopi, M., Demir, A.G., Caprio, L. and Previtali, B. (2019), "Limits and solutions in processing pure $\mathrm{Cu}$ via selective laser melting using a high-power single-mode fiber laser", The International fournal of Advanced Manufacturing Technology, Vol. 104 Nos 5/8, pp. 2473-2486.

Deng, D., Tang, Y., Huang, G., Lu, L. and Yuan, D. (2013), "Characterization of capillary performance of composite wicks for two-phase heat transfer devices", International fournal of Heat and Mass Transfer, Vol. 56 Nos 1/2, pp. 283-293.

Elnaggar, M. and Edwan, E. (2016), Heat Pipes for Computer Cooling Applications, Intech, pp. 52-77.

El-Wardany, T.I., She, Y., Jagdale, V.N., Garofano, J.K., Liou, J.J. and Schmidt, W.R. (2018), "Challenges in threedimensional printing of High-Conductivity copper", fournal of Electronic Packaging, Vol. 140 No. 2, doi: 10.1115/ 1.4039974 .

Esarte, J., Blanco, J.M., Bernardini, A. and San-José, J.T. (2017), "Optimizing the design of a two-phase cooling system loop heat pipe: wick manufacturing with the 3D selective laser melting printing technique and prototype testing", Applied Thermal Engineering, Vol. 111, pp. 407-419.

Espinosa, F.A.D., Peters, T.B. and Brisson, J.G. (2012), "Effect of fabrication parameters on the thermophysical properties of sinters wicks for heat pipe application", International fournal of Heat and Mass Transfer, Vol. 55 Nos 25/26, pp. 7471-7486.

Hale, R.S., Bonnecaze, R.T. and Hidrovo, C.H. (2014a), "Optimization of capillary flow through square micropillar arrays", International fournal of Multiphase Flow, Vol. 58, pp. 39-51.

Hale, R.S., Ranjan, R. and Hidrovo, C.H. (2014b), "Capillary flow through rectangular micropillar arrays", International Fournal of Heat and Mass Transfer, Vol. 75, pp. 710-717.

Jafari, D. and Wits, W.W. (2018), "The utilization of selective laser melting technology on heat transfer devices for thermal energy conversion applications: a review", Renewable and Sustainable Energy Reviews, Vol. 91, pp. 420-442.

Jafari, D., Wits, W.W. and Geurts, B.J. (2018), “Metal 3Dprinted wick structures for heat pipe application: capillary performance analysis", Applied Thermal Engineering, Vol. 143, pp. 403-414.

Jafari, D., van Alphen, K.J.H., Geurts, B.J., Wits, W.W., Gonzalez, L.C., Vaneker, T.H.J., Rahman, N.U., Römer, G. W. and Gibson, I. (2020), "Porous materials additively manufactured at low energy: single-layer manufacturing and characterization”, Materials \& Design, Vol. 191, p. 108654.

Krauss, H., Zeugner, T. and Zaeh, M.F. (2015), "Thermographic process monitoring in powderbed based additive manufacturing", AIP Conference Proceedings, presented at the 41st Annual Review of Progress in Quantitative Nondestructive Evaluation, pp. 177-183.
Lips, S., Sartre, V., Lefevre, F., Khandekar, S. and Bonjour, J. (2016), "Overview of heat pipe studies during the period 2010-2015”, Interfacial Phenomena and Heat Transfer, Vol. 4 No. 1, pp. 33-53.

Pogson, S.R., Fox, P., Sutcliffe, C.J. and O’Neill, W. (2003), "The production of copper parts using DMLR", Rapid Prototyping fournal, Vol. 9 No. 5, pp. 334-343.

Popovich, A., Sufiiarov, V., Polozov, I., Borisov, E., Masaylo, D. and Orlov, A. (2016), "Microstructure and mechanical properties of additive manufactured copper alloy", Materials Letters, Vol. 179, pp. 38-41.

Reay, D., Kew, P.A. and McGlen, R.J. (2014), Heat Pipes: Theory, Design, and Applications, 6th ed., Elsevier, pp. 1-91.

Richard, B., Pellicone, D. and Anderson, B. (2017), "Loop heat pipe wick fabrication via additive manufacturing", presented at the 47th International Conference on Environmental Systems, pp. 1-10.

Robinson, J., Arjunan, A., Stanford, M., Lyall, I. and Williams, C. (2021), "Effect of silver addition in copper-silver alloys fabricated by laser powder bed fusion in situ alloying", fournal of Alloys and Compounds, Vol. 857, p. 157561.

Semenic, T., Lin, Y.-Y. and Catton, I. (2008), "Thermophysical properties of biporous heat pipe evaporators", Fournal of Heat Transfer, Vol. 130 No. 2, p. 22602.

Singh, R., Akbarzadeh, A. and Mochizuki, M. (2009), "Effect of wick characteristics on the thermal performance of the miniature loop heat pipe", fournal of Heat Transfer, Vol. 131 No. 8, p. 82601.

Tang, Y., Deng, D., Lu, L., Pan, M. and Wang, Q. (2010), "Experimental investigation on capillary force of composite wick structure by IR thermal imaging camera", Experimental Thermal and Fluid Science, Vol. 34 No. 2, pp. 190-196.

Tang, Y., Tang, H., Li, J., Zhang, S., Zhuang, B. and Sun, Y. (2017), "Experimental investigation of capillary force in a novel sintered coppermesh wick for ultra-thin heat pipes", Applied Thermal Engineering, Vol. 115, pp. 1020-1030.

Wang, X.W., Ho, J.Y. and Leong, K.C. (2018), “An experimental investigation of single droplet impact cooling on hot enhanced surfaces fabricated by selective laser melting", International fournal of Heat and Mass Transfer, Vol. 120, pp. 652-670.

Zeng, J., Lin, L., Tang, Y., Sun, Y. and Yuan, W. (2017), "Fabrication and capillary characterization of micro-grooved wicks with reentrant cavity array", International fournal of Heat and Mass Transfer, Vol. 104, pp. 918-929.

Zhang, X., Sun, C., Pan, T., Flood, A., Zhang, Y., Li, L. and Liou, F. (2020), “Additive manufacturing of copper - H13 tool steel bi-metallic structures via Ni-based multiinterlayer”, Additive Manufacturing, Vol. 36, p. 101474.

\section{Corresponding author}

Adnen Mezghani can be contacted at: azm1131@psu.edu 